\title{
Nontuberculosis mycobacteria are the major causes of tuberculosis like lesions in cattle slaughtered at Bahir Dar Abattoir, northwestern Ethiopia
}

\author{
Anwar Nuru ${ }^{1,5^{*}}$ (D, Aboma Zewude ${ }^{1}$, Temesgen Mohammed', Biniam Wondale ${ }^{1}$, Laikemariam Teshome²,
} Muluwork Getahun ${ }^{4}$, Gezahegne Mamo ${ }^{3}$, Girmay Medhin ${ }^{1}$, Rembert Pieper ${ }^{6}$ and Gobena Ameni ${ }^{1}$

\begin{abstract}
Background: The main cause of bovine tuberculosis (bTB) is believed to be Mycobacterium bovis (M. bovis). Nontuberculosis mycobacteria (NTM) are neglected but opportunistic pathogens and obstacles for bTB diagnosis. This study aimed to isolate and characterize the mycobacteria organisms involved in causing TB-like lesions in cattle in northwestern Ethiopia.

Results: A total of 2846 carcasses of cattle were inspected for TB lesions. Ninety six tissues (including lymph nodes such as submandibular, retropharyngeal, tonsilar, mediatinal, bronchial and mesenteric, and organs such as lung, liver and kidney) with suspicious TB lesion(s) were collected and cultured on Lowenstein-Jensen medium. Twenty one showed culture growth, of which only 17 were identified containing acid fast bacilli (AFB) by Ziehl-Neelsen staining. Among the 17 AFB isolates 15 generated a polymerase chain reaction product of 1030 bp by gel electrophoresis based on the $16 \mathrm{~S}$ ribosomal RNA gene amplification. No M. tuberculosis complex species were isolated. Further characterization by Genotype Mycobacterium CM assay showed 6 isolates identified as M. peregrinum. Eight isolates represented by mixed species, which includes $M$. fortuitum-peregrinum (3 isolates), M. gordonae-peregrinum (3 isolates) and $M$. fortuitum-gordonae-peregrinum (2 isolates). One NTM could not be interpreted.

Conclusion: A significant number of NTM species were isolated from TB-like lesions of grazing cattle slaughtered at Bahir Dar Abattoir. Such finding could suggest the role of NTM in causing lesions in cattle. Further investigations are recommended on the pathogenesis of the reported NTM species in cattle, and if they have public health significance.
\end{abstract}

Keywords: Cattle, Nontuberculosis mycobacteria, TB-like lesion

\section{Background}

Bovine tuberculosis (bTB), which is primarily caused by Mycobacterium bovis (M. bovis) is an endemic disease of cattle in Ethiopia and distributed in almost all parts of the country. Although its current prevalence rate, at a national level, is unknown, previous Ethiopian studies have shown that the average herd prevalence of bTB in smallholder farms is $21.1 \%$ [1-4] and intensive dairy

\footnotetext{
* Correspondence: hamduanwar@yahoo.com

${ }^{1}$ Aklilu Lemma Institute of Pathobiology, Addis Ababa University, P.O. Box

1176, Addis Ababa, Ethiopia

${ }^{5}$ College of Veterinary Medicine and Animal Sciences, University of Gondar,

P.O. Box 346, Gondar, Ethiopia

Full list of author information is available at the end of the article
}

production systems is $49.3 \%[5,6]$. Other Ethiopian studies [7-15] undertaken at abattoirs have reported bTB in cattle based on TB-like lesion with an estimated average prevalence of $5.57 \%$. In addition, $M$. bovis was also recovered from TB lesions in cattle, spoligotyped, and their strain types were identified and reported by previous studies in Ethiopia [7, 9, 16-19]. Infection with $M$. bovis can be transmitted from cattle to humans, mainly through the consumption of contaminated milk and meat [20], although there is no evidence that this has happened in Ethiopia, where raw milk and meat consumption is widely habituated. Although the $M$. tuberculosis complex (MTBC) species are identified as 
strict pathogens of $\mathrm{TB}$ in human and animals, other mycobacteria species collectively referred to as nontuberculosis mycobacteria (NTM) also play a significant role as a source of infections [21]. However, there have been no studies to date conducted to identify the specific species of NTMs that are causing TB lesions in cattle in northwest Ethiopia. Presently fast, easy and sensitive molecular tools are available for the detection and identification of MTBC and NTM [22]. Thus, identification of mycobacteria is required using these molecular tools to guide therapy and for epidemiological purposes.

In the present study NTMs were predominantly isolated and characterized from TB-like lesions of cattle by molecular tools such as mycobacterium genus typing and Genotype Mycobacterium CM assay. $M$. peregrinum was the most dominant NTM species recovered from 6 isolates. Eight isolates represented by mixed species such as $M$. fortuitumperegrinum (3 isolates), M. gordonae-peregrinum (3 isolates) and $M$. fortuitum-gordonae-peregrinum (2 isolates). One NTM could not be interpreted even if it had a band pattern of 1,2,3 and 10, and no MTBC species were identified.

\section{Methods}

\section{Description of the study area and setting}

The study was conducted in cattle slaughtered at Bahir Dar Abattoir, which is located in Bahir Dar City of Amhara Regional State, northwest Ethiopia. Currently, Bahir Dar Abattoir is the only licensed slaughter house in Bahir Dar City, which fulfils the daily beef requirements of over 200,000 inhabitants of the city, peri-urban areas and its neighboring rural villages. Cattle slaughtered at the abattoir were mainly of the Zebu type and originated from different districts of Amhara Region and the neighboring Oromia Region (Amhara and Oromia regions are among the nine ethnically based regional states of Ethiopia, and have the largest number of livestock and human population compared to other regions).

\section{Sample collection and processing}

A total of 2846 cattle slaughtered from October 2014 to December 2015 at Bahir Dar Abattoir were thoroughly inspected for TB lesions. Parotid, mandibular, retropharyngeal, tonsilar, left and right bronchial, cranial and caudal mediastinal, brochial, tracheobronchial and mesenteric lymph nodes, and organs including the lungs, liver and kidneys were examined. The seven lobes of the two lungs were inspected externally and palpated. Each lobe was sectioned into approximately $2 \mathrm{~cm}$ thick slices to identify the lesions. Similarly, lymph nodes sliced into sections of a similar thickness and inspected for the presence of visible lesions. The animal was classified as having lesion when gross lesion(s) suggestive of bTB were found in any of the tissues examined. Each specimen was processed and cultured for the isolation of mycobacteria following standard procedure described by OIE [23]. In brief, the tissue samples were manually dissected in to small pieces and homogenized using a pestle and mortar. The homogenate decontaminated by an equal volume of $4 \% \mathrm{NaOH}$ and concentrated by centrifugation at $3000 \times \mathrm{g}$ for $15 \mathrm{~min}$. The sediment was neutralized with $2 \mathrm{~N} \mathrm{HCl}$ using phenol red as an indicator, and inoculated onto Lowenstein Jensen (LJ) glycerol and LJ pyruvate solid media slants. The culture media were incubated at $37{ }^{\circ} \mathrm{C}$ for 8 weeks, and considered negative if no visible growth was detected after the eighth week of incubation. Ziehl-Neelsen (ZN) staining microscopic examination was performed to select acid fast bacilli (AFB) positive isolates. Presumptive mycobacterial colonies were heat-killed at $85{ }^{\circ} \mathrm{C}$ for 45 min by mixing 2 loop-full of cells in $200 \mu \mathrm{l}$ distilled $\mathrm{H}_{2} \mathrm{O}$ for further molecular activities.

\section{Mycobacterium genus typing}

Multiplex polymerase chain reaction (mPCR) using six oligonucleotide primers was performed as described previously [24]. Primer pairs included were MYCGEN-F 5'AGA GTT TGA TCC TGG CTC AG-3', MYCGEN-R 5' TGC ACA CAG GCC ACA AGG GA-3', which amplify a specific PCR product from the $16 \mathrm{~S}$ rRNA gene of all know mycobacteria were used. MYCAV-R 5'-ACC AGA AGA CAT GCG TCT TG-3' and MYCINT-F 5'-CCT TTA GGC GCA TGT CTT TA-3' which amplify the hyper variable region of the $16 \mathrm{~S}$ rRNA gene of $M$. intracellulare (MYCINT-F) and M. avium (MYCAV-R), respectively. Two primers (TB1-F 5'-GAA CAA TCC GGA GTT GAC AA-3') and (TB1-R 5'-AGC ACG CTG TCA ATC ATG TA-3'), which target for the MPB70 gene were used to specify $M$. tuberculosis complex from the mycobacteria.

Amplification was done as recommended. In each run M. avium and M. bovis were included as a positive control with sterile water $\left(\mathrm{H}_{2} \mathrm{O}\right.$ Qiagen $)$ as a negative control. The PCR products were electrophoresed in $1.5 \%$ agarose gel, and the final image visualized under ultraviolet light.

\section{The GenoType ${ }^{\circledR}$ mycobacterium common Mycobacteria (CM) assay}

The GenoType ${ }^{\oplus}$ Mycobacterium CM assay (Hain Lifescience, Nehren Germany) was used to analyze NTM isolates at the species level, and the procedure described in the manual enclosed in the kit was followed to conduct the test. The assay involved DNA amplification targeting the 23S rRNA gene region, as recommended. Followed by the reverse hybridization to specific oligonucleotide probes immobilized on membrane strips, which was conducted on a shaking TwinCubator (Hain). The final result was interpreted based on the presence and absence of bands, and compared with the evaluation sheet provided with the kit. M. tuberculosis H37Rv, M. 
fortuitum and $M$. abscessus were used as appositive control while $\mathrm{H}_{2} \mathrm{O}$ Qiagen as a negative control.

\section{Ethical considerations}

The study was approved by Ethical Review Board (Ref. number IRB/05-02/2013) of the Aklilu Lemma Institute of Pathobiology, Addis Ababa University. Study permission also obtained Amhara Region Bureau of Agriculture Department of Animal Agency, and Municipality Office of Bahir Dar City.

\section{Results}

\section{Description of the study animals and tissues}

The vast majority of studied cattle was male $(88.7 \%$, $2524 / 2846)$ and zebu breed (99.9\%, 2842/2846). Seventy nine carcasses had lesion(s) suspected of bTB resulting in an overall animal level prevalence of $2.78 \%$ (79/2846). The animal level prevalence was defined as the number of cattle positive for TB-like lesion(s) per 100 cattle examined. From 79 positive cattle a total of 96 different tissues having TB-like lesions were collected, processed and cultured onto LJ media. Of which 21 showed culture growth, and only 17 colonies were identified containing mycobacteria by ZN staining with an overall AFB positivity of $17.7 \%$ (17/96). The 17 mycobacterial isolates were detected only from 12 slaughtered cattle, and the largest proportion was observed in the retropharyngeal lymph nodes $(75 \%)$ followed by submandibular and the kidney tissues (each with 50\% proportion). The type and number of tissues identified with suspicious TB lesion(s), and their corresponding AFB positivity are indicated in Table 1.

\section{Identification and speciation of nontuberculosis mycobacteria}

Among the 17 AFB positive mycobacterial isolates 15 generated a PCR product of 1030 bp by gel electrophoresis (Fig. 1), and consequently identified as NTM.

Further characterization of the 15 NTM by using Genotype Mycobacterium CM assay revealed that 14 isolates identified at the species level and 1 NTM could
Table 1 Cattle tissues identified with suspicious tuberculosis lesions and mycobacteria

\begin{tabular}{lll}
\hline Type of tissue & $\begin{array}{l}\text { Number of tissue with } \\
\text { lesion(s) }\end{array}$ & $\begin{array}{l}{ }^{a} \text { AFB positive, } \\
+n(\%)\end{array}$ \\
\hline $\begin{array}{l}\text { Submandibular } \\
\text { lymph node }\end{array}$ & 2 & $1(50.0)$ \\
$\begin{array}{l}\text { Retropharyngeal } \\
\text { lymph node }\end{array}$ & 4 & $3(75.0)$ \\
$\begin{array}{l}\text { Tonsilar lymph node } \\
\text { Mediastinal lymph }\end{array}$ & 3 & $1(33.3)$ \\
node & 12 & $1(8.33)$ \\
$\begin{array}{l}\text { Bronchial lymph node } \\
\text { Mesenteric lymph }\end{array}$ & 10 & $1(10.0)$ \\
node & 43 & $3(7.00)$ \\
Lung tissue & 6 & $2(33.3)$ \\
Liver tissue & 14 & $4(28.6)$ \\
Kidney tissue & 2 & $1(50.0)$ \\
Total & 96 & $17(17.7)$
\end{tabular}

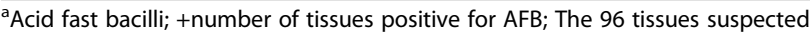
of having tuberculosis lesion(s) were identified from 79 of 2846 cattle slaughtered at Bahir Dar Abattoir, northwestern Ethiopia. Of which 17 tissues identified containing mycobacteria by Ziehl-Neelsen staining and were recorded from carcasses of only 12 cattle

not be interpreted even if it has a band pattern of $1,2,3$ and 10 (Fig. 2). Among the 14 isolates with defined NTM species, 6 isolates were recognized as M. peregrinum, and the remaining 8 represented mixed species including $M$. fortuitum-peregrinum (3 isolates), $M$. gordonae-peregrinum (3 isolates), and M. fortuitumgordonae-peregrinum (2 isolates).

\section{Discussion}

The overall prevalence of bTB from gross suspected TB lesion(s) in the present study was $2.78 \%$ which is comparable to $2.7 \%$ reported by Bekele and Belay [10], but lower than other findings ranging from $3.5 \%$ to $10.2 \%$ $[7-9,11-15,25]$. These variations could be explained by many factors including differences in the disease status in the animal populations, the sample size and the type of production system from where the slaughtered cattle were originated. Breed of animals that are slaughtered in

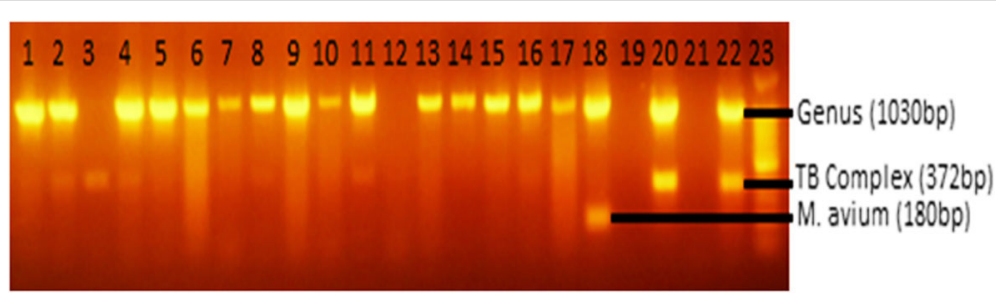

Fig. 1 Gel electrophoresis of PCR products from AFB isolated from cattle tissue containing TB-like lesion(s). The Seventeen acid fast bacilli positive tuberculosis lesions were identified from 79 tissues of 2846 cattle slaughtered at Bahir Dar Abattoir, northwest Ethiopia. Lanes 1-17 = test isolates, Lane $18=$ M. avium (positive control), Lane $19=$ missed out, Lane $20=$ M. bovis (positive control), Lane $21=$ Qiagen $\mathrm{H}_{2} \mathrm{O}$ (negative control), Lane $22=$ M. tuberculosis (positive control), and Lane $23=100$ bp DNA ladder 


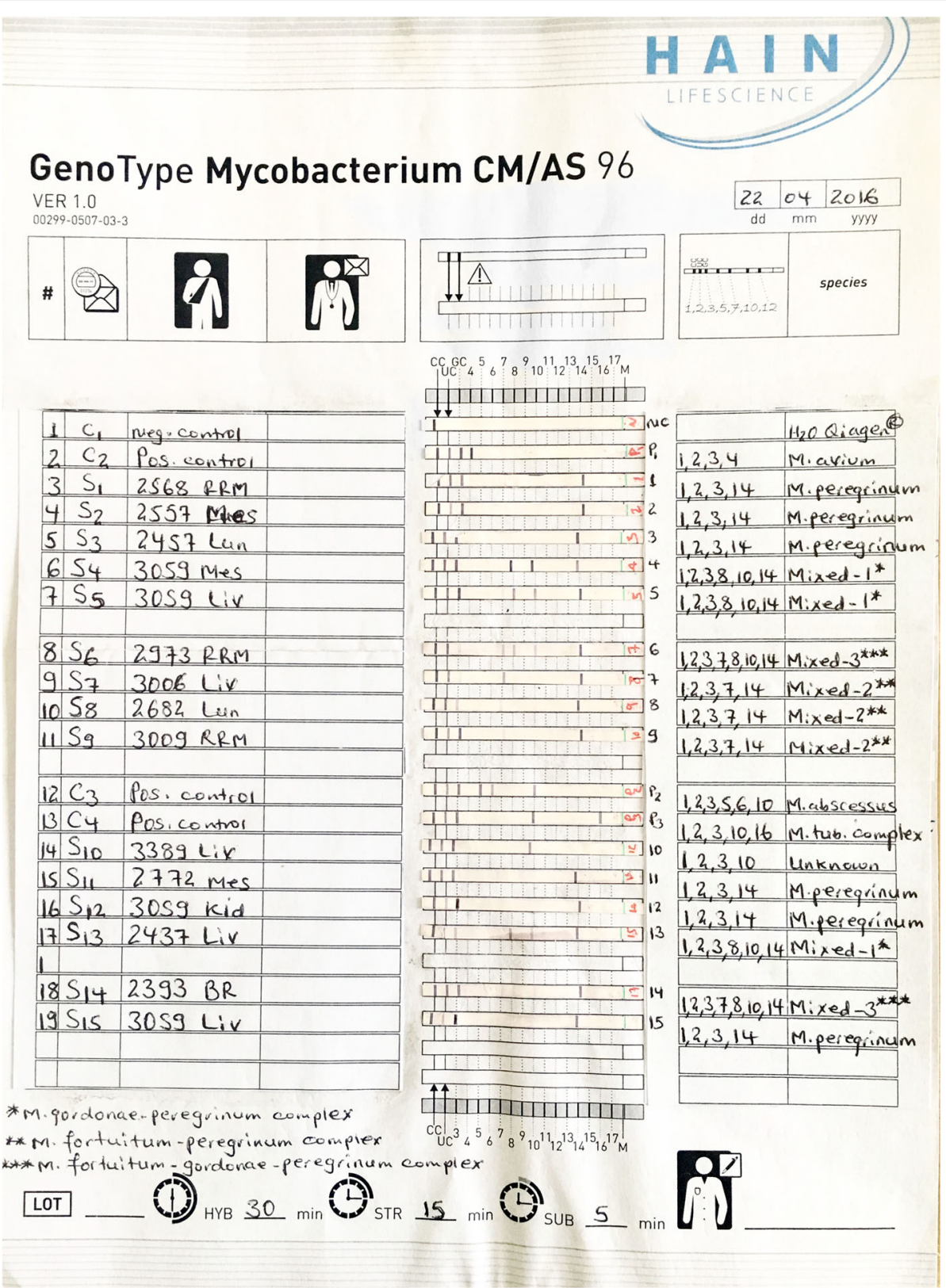

Fig. 2 Nontuberculosis mycobacteria species identified from cattle tissue containing TB-like lesion(s). *Mixed-1: M. gordonae-peregrinum; ${ }^{* *}$ Mixed-2: M. fortuitum-peregrinum; ***Mixed-3: M. fortuitum-gordonae-peregrinum; fifteen of the 17 isolates with acid fast bacilli showed bands at 1030 bp by Gel electrophoresis and identified as nontuberculosis mycobacteria (NTM). Further characterization by GenoType ${ }^{\oplus}$ mycobacterium CM showed 14 of the 15 NTMs defined at the species level and the remaining 1 NTM (Sample code: $S_{10}$ ) could not be interpreted

the abattoirs and subjective differences in identifying TB lesions could also be considered for the disparities observed. The low prevalence of bTB in this study could be explained by the fact that the vast majority of cattle in the current study were Zebu and from non-intensive smallholder farms as well as most of the cattle were originated from northwest Ethiopia, where the overall prevalence of bTB was reported very low [10]. Moreover, the TB-like lesions might not always be of mycobacterial origin, rather they could also be caused by other granuloma forming organisms like Nocardia and Corynebacterium species [26], parasites and other non-specific reactions [27, 28].

The overall culture yield of AFB from visible lesions in the present study was $17.7 \%$, which is slightly higher than $11 \%$ reported previously in Ethiopia [7], but lower proportion when it is compared to $38.1 \%$ recorded in Jimma Municipality Abattoir, southwest Ethiopia [10]. The observed differences could also be attributed to the 
subjective differences in identifying TB lesions, which were subjected to $\mathrm{ZN}$ staining microscopic examination across the study sites.

Different NTM species were identified in this study from isolates with positive AFB, notably $M$. fortuitum, $M$. gordonae and $M$. peregrinum. The NTM species such as $M$. fortuitum and $M$. gordonae are so ubiquitous that they have previously been recovered from cattle in Ethiopia [7, 29], and human, animals and the environment elsewhere in Africa [28, 30-32]. Mycobacterium peregrinum, which is a rapidly growing, ubiquitous and an opportunistic but potentially pathogenic NTM [33] was isolated more frequently in this study. Similar previous studies in Ethiopia [7] and Zimbabwe [34] have also reported M. peregrinum from cattle as well. Moreover, miscellaneous human infections, more specifically skin and lung infections were also found associated with $M$. peregrinum in Japan [35] and Brazil [36], respectively. The high rate of $M$. peregrinum isolation from lesions in the present study can suggest that this species of NTM is abundant and has high pathogenicity to cause infection in cattle in the study area as compared to other NTM species including $M$. fortuitum and $M$. gordonae. However, the role of these NTMs in TB disease causation in cattle and their zoonotic implication is not known in our cases, and these will be the objective for further investigations. Moreover, M. fortuitum and $M$. gordonae have been reported to elicit reactions to purified protein derivative bovine based skin tests in cattle [37]. As a result the isolation of these species in the present study emphasized further studies as mycobacteria other than $M$. bovis may interfere with current bTB diagnostic tests and ensuing in false positive test results [38].

\section{Conclusion}

This study has isolated NTMs, notably $M$. fortuitum, $M$. gordonae and $M$. peregrinum from TB-like lesions of grazing cattle, and these findings suggest an important role of NTM in causing lesions in cattle. However, the pathogenesis of NTM species in cattle, the epidemiology (including sampling from environmental sources such as water and soil), their interactions with bTB and the zoonotic link between animal and humans is not known and needs further studies.

\footnotetext{
Abbreviations

AFB: Acid fast bacilli; Bp: Base pair; bTB: Bovine tuberculosis; CIDT: Comparative intradermal tuberculin; CM: Common mycobacteria; L: Lowenstein Jensen; MTBC: Mycobacterium tuberculosis complex; NTM: nontuberculosis mycobacteria; PCR: Polymerase chain reaction PPD-B: Purified protein derivative bovine; TB: Tuberculosis; ZN: Ziehl-Neelsen
}

\section{Acknowledgements}

This study was jointly funded by the National Institute of Health (NIH, USA) through its H3Africa Program (Grant number: U01HG0074720l), Addis Ababa University through its Thematic Research Program, and University of Gondar. Tiru Alem, Gashaw Yitayew, Aschalew Admasu, and staff of Aklilu Lemma
Institute of Pathobiology and Bahir Dar Animal Diseases Investigation and Diagnostic Laboratory were acknowledged for their technical support.

\section{Funding}

This study was jointly funded by the National Institute of Health (NIH, USA) through its H3Africa Program (Grant number: U01HG0074720l), Addis Ababa University through its Thematic Research Program, and University of Gondar.

\section{Availability of data and materials}

The data set(s) supporting the results of this article are included within the article.

\section{Authors' contributions}

AN participated in the design of the study, data collection, laboratory work, statistical analysis, interpretation of the data and drafted the manuscript. AZ participated in the identification of suspected TB lesions at the abattoir and interpretation of the data. TM participated in performing multiplex PCR and gel electrophoresis, and interpretation of the data. BW participated in performing multiplex PCR and gel electrophoresis, and interpretation of the data. MG participated in performing NTM species identification by GenoType Mycobacteria CM assay and interpretation the data. GM participated in the design of the study, interpretation of the data and reviewed the draft manuscript. GM participated in the design of the study, statistical analysis and reviewed the draft manuscript. RP participated in the design of the study and reviewed the draft manuscript. GA participated in the design of the study, interpretation of the data and reviewed the draft manuscript. All authors read and approved the final manuscript.

\section{Ethics approval and consent to participate}

The study was approved by Ethical Review Board (Ref. number IRB/05-02/ 2013) of the Aklilu Lemma Institute of Pathobiology, Addis Ababa University. However, consent to participate is not applicable for this study.

\section{Consent for publication}

Not applicable

\section{Competing interests}

The authors declare that they have no competing interests.

\section{Publisher's Note}

Springer Nature remains neutral with regard to jurisdictional claims in published maps and institutional affiliations.

\section{Author details}

${ }^{1}$ Aklilu Lemma Institute of Pathobiology, Addis Ababa University, P.O. Box 1176, Addis Ababa, Ethiopia. ${ }^{2}$ Animal Diseases Investigation and Diagnostic Laboratory, Amhara Region Bureau of Agriculture, P. 0. Box 70, Bahir Dar, Ethiopia. ${ }^{3}$ College of Veterinary Medicine and Agriculture, Addis Ababa University, P.O. Box 34, Debre Zeit, Ethiopia. ${ }^{4}$ Ethiopian Public Health Institute, P. O. Box181689, Addis Ababa, Ethiopia. ${ }^{5}$ College of Veterinary Medicine and Animal Sciences, University of Gondar, P.O. Box 346, Gondar, Ethiopia. ${ }^{6}$ J. Craig Venter Institute, 9704 Medical Center Drive, Rockville, MD, USA.

Received: 11 October 2016 Accepted: 9 August 2017

Published online: 15 August 2017

\section{References}

1. Mamo G, Abebe F, Worku Y, Hussein N, Legesse M, Tilahun G, et al. Bovine tuberculosis and its associated risk factors in pastoral and agro-pastoral cattle herds of afar region, Northeast Ethiopia. J Vet Med Anim Health. 2013;5(6):171-9.

2. Romha G, Gebre egziabher G, Ameni G. Assessment of bovine tuberculosis and its risk factors in cattle and humans, at and around Dilla town, southern Ethiopia. Anim Vet Sci. 2014;2(4):94-100

3. Zeru F, Romha G, Berhe G, Mamo G, Sisay T, Ameni G. Prevalence of bovine tuberculosis and ssessment of cattle owners' awareness on its public health implication in and around Mekelle, northern Ethiopia. J Vet Med Anim Health. 2014;6(6):159-67.

4. Nuru A, Mamo G, Teshome L, Zewdie A, Medhin G, Pieper R, Ameni G. Bovine tuberculosis and its risk factors among dairy cattle herds in and around Bahir Dar City. Northwest Ethiopia Ethiop Vet J. 2015;19(2):27-40. 
5. Firdessa R, Tschopp R, Wubete A, Sombo M, Hailu E, Erenso G, et al. High prevalence of bovine tuberculosis in dairy cattle in Central Ethiopia: implications for the dairy industry and public health. PLoS One. 2012;7(12):e52851.

6. Tigre W, Alemayehu G, Abetu T, Ameni G. Preliminary study on the epidemiology of bovine tuberculosis in Jimma town and its surroundings, southwestern Ethiopia. Afr J Microbiol Res. 2012;6(11):2591-7.

7. Berg S, Firdessa R, Habtamu M, Gadisa E, Mengistu A, Yamuah L, et al. The burden of Mycobacterial disease in Ethiopian cattle: implications for public health. PLoS One. 2009;4(4):e5068.

8. Demelash B, Inangolet F, Oloya J, Asseged B, Badaso M, Yilkal A, et al. Prevalence of bovine tuberculosis in Ethiopian slaughter cattle based on post-mortem examination. Trop Anim Health Prod. 2009;41(5):755-65.

9. Ameni G, Desta F, Firdessa R. Molecular typing of Mycobacterium bovis isolated from tuberculosis lesions of cattle in north eastern Ethiopia. Vet Rec. 2010;167:138-41.

10. Bekele B, Belay I. Evaluation of routine meat inspection procedure to detect bovine tuberculosis suggestive lesions in Jimma municipal abattoir, south West Ethiopia. Global Veterinaria. 2011;6:172-9.

11. Ewnetu L, Melaku A, Birhanu A. Bovine tuberculosis prevalence in slaughtered cattle at Akaki municipal abattoir based on meat inspection methods. Global Veterinaria. 2012:9(5):541-5.

12. Mekibeb A, Fulasa T, Firdessa R, Hailu E. Prevalence study on bovine tuberculosis and molecular characterization of its causative agents in cattle slaughtered at Addis Ababa municipal abattoir, Central Ethiopia. Trop Anim Health Prod. 2013;45(3):763-9.

13. Biru A, Ameni G, Sori T, Desissa F, Teklu A, Tafess K. Epidemiology and public health significance of bovine tuberculosis in and around Sululta District, Central Ethiopia. Afr J Microbiol Res. 2014;8(24):2352-8.

14. Zeru F, Romha G, Ameni G. Gross and molecular characterization of mycobacterium tuberculosis complex in Mekelle town municipal abattoir. Northern Ethiopia Global Veterinaria. 2013;11(5):541-6.

15. Terefe D. Gross pathological lesions of bovine tuberculosis and efficiency of meat inspection procedure to detect-infected cattle in Adama municipal abattoir. J Vet Med Anim Health. 2014;6(2):48-53.

16. Ameni G, Aseffa A, Engers H, Young D, Gordon S, Hewinson G. Vordermeier. High prevalence and increased severity of pathology of bovine tuberculosis in Holsteins compared to zebu breeds under field cattle husbandry in central Ethiopia. Clin Vaccine Immunol. 2007;14:1356-61.

17. Biffa D, Skjerve E, Oloya J, Bogale A, Abebe F, et al. Molecular characterization of Mycobacterium Bovis isolates from Ethiopian cattle. BMC Vet Res. 2010;6:28

18. Firdessa R, Berg S, Hailu E, Schelling E, Gumi B, Erenso G, et al. Mycobacterial lineages causing pulmonary and extrapulmonary tuberculosis, Ethiopia. Emerg Infect Dis. 2013;19(3):460-3.

19. Ameni G, Tadesse K, Hailu E, Deresse Y, Medhin G, Aseffa A, et al. Transmission of mycobacterium tuberculosis between farmers and cattle in central Ethiopia. PLoS One. 2013:8(10):e76891.

20. de la Rua-Domenech R. Human Mycobacterium bovis infection in the United Kingdom: incidence, risks, control measures and review of the zoonotic aspects of bovine tuberculosis. Tuberculosis. 2006;86:77-109.

21. van Ingen J, Boeree MJ, Dekhuijzen PN, van Soolingen D. Environmental sources of rapid growing nontuberculous mycobacteria causing disease in humans. Clin Microbiol Infect. 2009:15:888-93.

22. Ting SW, Chia CL, Hsin CL. Current situations on identification of nontuberculous mycobacteria. J Biomed Lab Sci. 2009;21:1-6.

23. OIE. Bovine tuberculosis. Manual of diagnostic tests and vaccines for terrestrial animals (mammals, birds and bees), vol. Chapter 2.4.7; 2009. p. 683.

24. Wilton S, Cousins D. Detection and identification of multiple mycobacterial pathogens by DNA amplification in a single tube. PCR Methods Appl. 1992;1(4):269-73.

25. Beyi AF, Gezahegne KZ, Mussa A, Ameni G, Ali MS. Prevalence of bovine tuberculosis in dromedary camels and awareness of pastoralists about its zoonotic importance in eastern Ethiopia. J Vet Med Anim Health. 2014:6(4):109-15.

26. Grist A. Bovine meat inspection - anatomy, physiology and disease conditions. 2nd ed. Nottingham: Nottingham University Press; 2009.

27. Shitaye JE, Getahun B, Alemayehu T, Skoric M, Treml F, Fictum P, et al. A prevalence study of bovine tuberculosis by using abattoir meat inspection and tuberculin skin testing data, histopathological and IS6110 PCR examination of tissues with tuberculous lesions in cattle in Ethiopia. Veterinarni Medicina. 2006;51:512-22.
28. Diguimbaye-Djaibe C, Vincent V, Schelling E, Hilty M, Ngandolo R, Mahamat HH, et al. Species identification of non-tuberculous mycobacteria from humans and cattle of Chad. Schweiz Arch Tierheilkd. 2006;148(5):251-6.

29. Ameni G, Vordermeier M, Firdessa R, Aseffac A, Hewinson G, Gordon SV et al. Mycobacterium tuberculosis infection in grazing cattle in central Ethiopia. Vet J. 2011;188(3):359-61.

30. Katale BZ, Mbugi EV, Botha L, Keyyu JD, Kendall S, Dockrell HM, et al. Species diversity of non-tuberculous mycobacteria isolated from humans, livestock and wildlife in the Serengeti ecosystem, Tanzania. BMC Infect Dis. 2014;14:616.

31. Egbe NF, Muwonge A, Ndip L, Kelly RF, Sander M, Tanya V, et al. Abattoir-based estimates of mycobacterial infections in Cameroon. Sci Rep. 2016:6:24320.

32. Malama S, Munyeme M, Mwanza S, Muma JB. Isolation and characterization of non tuberculous mycobacteria from humans and animals in Namwala District of Zambia. BMC Research Notes. 2014;7:622.

33. Kamijo F, Uhara H, Kubo H, Nakanaga K, Hoshino Y, Ishii N, Okuyama R. A case of mycobacterial skin disease caused by Mycobacterium peregrinum, and a review of cutaneous infection. Case Rep Dermatol. 2012;4(1):76-9.

34. Padya L, Chin'ombe N, Magwenzi M, Mbanga J, Ruhanya V, Nziramasanga P. Molecular identification of mycobacterium species of public health importance in cattle in Zimbabwe by $16 \mathrm{~S}$ rRNA gene sequencing. Open Microbiol J. 2015;9:38-42.

35. Sawahata M, Hagiwara E, Ogura T, Komatsu S, Sekine A, Tsuchiya N, et al. Pulmonary mycobacteriosis caused by Mycobacterium Peregrinum in a young, healthy man. Nihon Kokyuki Gakkai Zasshi. 2010:48(11):866-70.

36. Wachholz PA, Sette CS, do Nascimento DC, Soares CT, Diório SM, Masuda PY. Mycobacterium peregrinum skin infection: Case Report J Cutan Med Surg. 2015; [Epub ahead of print].

37. Bercovier $\mathrm{H}$, Vincent $\mathrm{V}$. Mycobacterial infections in domestic and wild animals due to Mycobacterium Marinum, M. Fortuitum, M. Chelonae, M. Porcinum, M. Farcinogenes, M. Smegmatis, M. Scrofulaceum, M. Xenopi, M. Kansasii, M. Simiae and M. Genavense. Rev - Off Int Epizoot. 2001;20:265-90.

38. Thacker TC, Robbe-Austerman S, Harris B, Van Palmer M, Waters WR. Isolation of mycobacteria from clinical samples collected in the United States from 2004 to 2011. BMC Vet Res. 2013;9:100

\section{Submit your next manuscript to BioMed Central and we will help you at every step:}

- We accept pre-submission inquiries

- Our selector tool helps you to find the most relevant journal

- We provide round the clock customer support

- Convenient online submission

- Thorough peer review

- Inclusion in PubMed and all major indexing services

- Maximum visibility for your research

Submit your manuscript at www.biomedcentral.com/submit
) Biomed Central 